\title{
Student Opinions on the Importance and Detail of the Accumulation of Anatomy Knowledge Integrating General Surgery
}

\author{
Erengül Boduç ${ }^{1}$, Tülay Diken Allahverdi ${ }^{2}$ \\ ${ }^{1}$ Department of Anatomy, Faculty of Medicine, Kafkas University, Kars, Turkey \\ ${ }^{2}$ Department of General Surgery, Faculty of Medicine, Kafkas University, Kars, Turkey \\ Received: 02 October 2020, Accepted: 09 December 2020, Published online: 31 December 2020 \\ (C) Ordu University Institute of Health Sciences, Turkey, 2020
}

\begin{abstract}
Objective: The aim of the study is to create an original study that guides the anatomy and surgical branches and supports education within the framework of their opinions by raising awareness on this issue in medical faculty students.

Methods: The study was carried out on the fourth, fifth and sixth year medical students of Kafkas University Medicine Faculty in the 2019-2020 academic year. Data collection questions were prepared with a five-point Likert scale. The answers given by the students were automatically analyzed through the web system and the results were obtained through the software

Results: The participation of the students to the opinions of the questions 1, 2, 4, 8, 10 and 12 is quite high $(73.2 \%, 74.6 \%, 56.3 \%, 67.6 \%, 52.1 \%, 62 \%)$. In general, the students want the integration of anatomy into clinical branches in a more up-to-date manner, apart from the traditional anatomy course.

Conclusion: This study was conducted for the importance and awareness of the integration of clinical and anatomy branches with each other. Student opinions were taken to emphasize the importance of the study. Anatomy basis is very important for surgical branches. Apart from classical anatomy education, anatomy education should keep up with technological developments and should be more integrated with clinical branches.
\end{abstract}

Key words: Anatomy education, Clinical anatomy, Five likert test

Suggested Citation: Boduc E, Diken Allahverdi T. Student Opinions on the Importance and Detail of the Accumulation of Anatomy Knowledge Integrating General Surgery. Middle Black Sea Journal of Health Science, 2020; 6(3):385-389.

\section{Address for correspondence/reprints:}

Erengul Boduc

Telephone number: +90 (530) 7849586

ORCID-ID 0000-0001-8872-1993

E-mail: erenboduc@gmail.com

DOI: $10.19127 / \mathrm{mbsjohs.803373}$

\section{Introduction}

In anatomy education, cadaver has been an important object throughout history (McLachlan et al., 2004; Biasutto et al., 2005). In recent years, developing technology with 3D software programs, as well as cadaver, has shown itself in a very eyecatching way in the field of anatomy (Rizzolo and Stewart, 2006; Hoyek et al., 2014; Bahsi et al., 2020). Anatomy department in every faculty in the world and in our country has made its way, some of them are benefiting from digital platform, some of them continue their course flow with both digital and 
cadaver, some cadaver and model, and some only with model (Older, 2004; Estai and Bunt, 2016;)

The quality of the anatomy education students receive significantly affects the success of the surgical courses and the training of qualified physicians and surgeons (Singh et al., 2015). When we examine this issue; Students love the anatomy education they receive and are interested in surgical lessons or the anatomy education they receive causes phobia in the students and decreases their interest in surgical lessons. The effect of anatomy education on students can determine two extreme situations, such as cooling the student from the medical school or, on the contrary, making the student a good physician (Kagan, 2002; Singh et al., 2015; Bahsi et al., 2017).

Unfortunately, an effective education cannot be provided in medical faculties when the basic sciences, which include the anatomy course, are not integrated with the surgical units. In addition to having a good anatomy education, the students should take the education together in anatomy and surgical branches so that the physician candidates can integrate the training they have basically received into the clinic (Fitzpatrick et al., 2001; Are et al., 2009; Ozcan et al., 2015)

When the basic sciences, which also include the anatomy course, are not integrated with surgical units, unfortunately, an effective education cannot be provided in medical faculties. In addition to having a good anatomy education, the students should take the education of anatomy and surgical branches together so that the physician candidates can integrate the training they have basically received into the clinic. For example, the better the branches such as histology, pharmacology, biochemistry can be integrated with the departments of pathology and internal medicine, the more rational and dynamic education progresses (Sugand et al., 2010; Heisler, 2011; Singh et al., 2015). Thus, physicians who know what they are doing and think rationally serve human health.

In this study, it was planned to conduct a data collection study that presents opinions about the compatibility of anatomy and surgery lessons. The aim of the study is to create an original study that guides the anatomy and surgical branches and supports education within the framework of their opinions by raising awareness on this issue in medical faculty students. In this way, education can be supported with integrated sessions that concern not only anatomy but all other branches, and student views can also be effective on this issue.

\section{Methods}

This study was approved by the ethics committee of Faculty of Health Sciences Kafkas University (Approval number: 2020/6/decision 01). The study was carried out on the fourth, fifth and sixth year medical students of Kafkas University Medicine Faculty in the 2019-2020 academic year. The data collection questionnaire was not sent to the first, second and third year students since they have not yet taken general surgery and other clinical courses. The questions asked in the data collection form were designed by literature review. The data collection forms used in the study were prepared on the web and sent to the students by e-mail. 71 students answered the questions in the data collection form. Data collection questions were prepared with a five-point Likert scale (totally agree, agree, undecided, disagree, totally disagree) (Gozil et al., 2006). The answers given by the students were automatically analyzed through the web system and the results were obtained through the software.

\section{Statistical analysis}

The fourth, fifth and sixth year medical students were compared according to the answers given by the students. Statistical analysis was carried out using SPSS 22.0 version software program for Windows. Descriptive statistics for categorical variables are expressed as frequency and percentage values. Data collection surveys were conducted with fourth, fifth and sixth grade students collectively. The questionnaires could not be applied separately because there is a great difference in the number of students in each class. Therefore, a comparative statistic could not be made.

\section{Results}

The answers given by the students to each question are shown in Table 1. In the first question; $73.2 \%$ of the students completely agreed, $25.4 \%$ only agreed, and $1.4 \%$ were indecisive. No one marked completely disagree and disagree in this question. In the second question; $74.6 \%$ of the students completely agreed, $21.1 \%$ only agreed, and $4.3 \%$ were indecisive. Again, in this question, no one marked completely disagree and disagree. In the third question; $42.3 \%$ of the students totally agreed, $38 \%$ only agreed, $11.3 \%$ were undecided, 5.6 did not agree totally and 2.4 did not agree. In the fourth question; $56.3 \%$ of the students totally agreed, $26.8 \%$ only agreed, $8.4 \%$ were undecided and 8.5 did not agree. No one marked completely disagree in this question. In the fifth question; $40.8 \%$ of the students totally agreed, $25.4 \%$ only agreed, $16,9 \%$ were undecided, 
2,8 did not agree totally and 14,1 did not agree. In sixth question; $50.7 \%$ of the students totally agreed, $23.9 \%$ only agreed, $11.3 \%$ were undecided, $2,8 \mathrm{did}$ not agree totally and 11.3 did not agree. In the seventh question; $50.7 \%$ of the students totally agreed, $28.2 \%$ only agreed, $14.1 \%$ were undecided, 4.3 did not agree totally and 2.7 did not agree. In the eighth question; $67.6 \%$ of the students totally agreed, $22.5 \%$ only agreed, $8.5 \%$ were undecided and 1.4 did not agree. No one marked completely disagree in this question. In the ninth question; $29.6 \%$ of the students totally agreed, $35.2 \%$ only agreed, $16.9 \%$ were undecided,
2.8 did not agree totally and 15.5 did not agree. In the tenth question; $52.1 \%$ of the students totally agreed, $25.5 \%$ only agreed, $12.7 \%$ were undecided, $1.4 \mathrm{did}$ not agree totally and 11.3 did not agree. In the eleventh question; $28.2 \%$ of the students totally agreed, $47.9 \%$ only agreed, $12.7 \%$ were undecided, 2.7 did not agree totally and 8.5 did not agree. In twelfth question, $62 \%$ of the students totally agreed, $31 \%$ only agreed, $1.3 \%$ were undecided, 2.9 did not agree totally and 2.6 did not agree.

Table 1. Frequency (f) percentages of the first and second year students' answers to the questions

\begin{tabular}{|c|c|c|c|c|c|}
\hline Medicine Faculty Students' 4th, 5th and 6th grade n:71 & \multicolumn{5}{|c|}{ ANSWERS } \\
\hline Questiones & 5 & 4 & 3 & 2 & 1 \\
\hline 1-A good anatomy education infrastructure is required for the general surgery branch. & 73,2 & 25,4 & 1,4 & - & - \\
\hline $\begin{array}{l}\text { 2-For the general surgery course, I need topographic and three-dimensional anatomy rather than } \\
\text { systematic anatomy. }\end{array}$ & 74,6 & 21,1 & 4,3 & - & - \\
\hline 3- I need a (theoretical) repetition of anatomy knowledge before the general surgery course. & 42,3 & 38 & 11,3 & 5,6 & 2,4 \\
\hline 4- I need (Practically) knowledge of anatomy. & 56,3 & 26,8 & 8,4 & - & 8,5 \\
\hline $\begin{array}{l}\text { 5- Before the general surgery course, I need both theoretical and three-dimensional visual } \\
\text { anatomy knowledge. }\end{array}$ & 40,8 & 25,4 & 16,9 & 2,8 & 14,1 \\
\hline $\begin{array}{l}\text { 6- Anatomy education with models and three-dimensional digital visuals is ideal to lay the } \\
\text { groundwork for upper classes of surgery. }\end{array}$ & 50,7 & 23,9 & 11,3 & 2,8 & 11,3 \\
\hline $\begin{array}{l}\text { 7- Anatomy education with cadavers is ideal to prepare the ground for surgery lessons in higher } \\
\text { classes. }\end{array}$ & 50,7 & 28,2 & 14,1 & 4,3 & 2,7 \\
\hline $\begin{array}{l}\text { 8- The most ideal anatomy training is given by integrating cadavers, models and three- } \\
\text { dimensional digital images to prepare the ground for surgical lessons in upper classes. }\end{array}$ & 67,6 & 22,5 & 8,5 & - & 1,4 \\
\hline $\begin{array}{l}\text { 9- Anatomy education with models and digital images cannot complement the perception of } \\
\text { reality encountered in surgical lessons. }\end{array}$ & 29,6 & 35,2 & 16,9 & 2,8 & 15,5 \\
\hline $\begin{array}{l}\text { 10- It is seen that even cadaveric education is lacking in completing the perception of reality in } \\
\text { surgical lessons, while anatomy education with only models and digital models will be } \\
\text { insufficient in medical education. }\end{array}$ & 52,1 & 25,5 & 12,7 & 1,4 & 11,3 \\
\hline $\begin{array}{l}\text { 11- Reality perception discovered and acquired in living tissue in the general surgery clinic is the } \\
\text { enhanced version of the anatomy lesson. }\end{array}$ & 28,2 & 47,9 & 12,7 & 2,7 & 8,5 \\
\hline $\begin{array}{l}\text { 12- two- and three-dimensional anatomy perception such as radiological anatomy, } \\
\text { ultrasonographic anatomy and laparoscopic anatomy are needed in the general surgery clinic. } \\
\text { In order to understand these, a good knowledge of anatomy and a good anatomy repetition before } \\
\text { the lesson is required. }\end{array}$ & 62 & 31 & 1,3 & 2,9 & 2,6 \\
\hline
\end{tabular}

5: Totally agree (\%), 4: Agree (\%), 3: Undecided (\%), 2: Totally Disagree (\%). 1: Disagree (\%)

\section{Discussion}

Anatomy is like the mother of medical education (Murgitroyd et al., 2015). Students grasp the importance and seriousness of medical school with the anatomy lesson, which is the first step to medicine (Cetkin et al., 2016). In addition, the foundation of surgical branches is based on anatomy education. Technological advances in recent years have brought many innovations to anatomy education. 3D digital software, plastination technique and $3 \mathrm{~d}$ models have enabled the development of anatomy education (Gunderman and Wilson, 2005; Lewis et al., 2014). Examination of anatomy from different dimensions with the developing technology has increased the importance of the interaction of this branch of science with surgical branches (Fitzpatrick et al., 2001; Ozcan et al., 2015).

The aim of this study is to emphasize the importance of anatomy-surgery branches interaction awareness with student views. Almost all of the students (73.2\%) agreed that a good anatomy foundation is necessary for general surgery. This situation has supported the importance of anatomy education in the literature as the basis of surgical branches. Before the general surgery course, instead of the classical systematic anatomy, which is taught theoretically, topographic and 3D anatomy practice lesson is a more preferred situation for students $(56.3 \%)$. This can also be interpreted as follows; Instead of an intense anatomy course based on memorization, an anatomy training based on visual memory and practice, which includes the anatomical neighborhood of the organs and their interactions with other organs necessary for general surgery, can be considered. The students gave equal notice $(50.7 \%)$ about learning anatomy with only cadavers or taking only 3-dimensional software and models. The reason for not adopting too much education in 
which only cadaver is shown may be the exam anxiety in the cadaver or the feeling of anxiety towards the cadaver.

Most of the students want an integrated anatomy education model based on three-dimensional software, models and cadaver association in preparation for surgical lessons (67.6\% totally agree, $22.5 \%$ agree). In addition to this view, most students agree that anatomy training with models and digital images cannot complement the perception of reality encountered in surgical lessons. But a small number of students disagree with this view. In other words, it can be thought that they agree with the view that three-dimensional software and visuals meet anatomy education before surgical lessons.

While it was observed that even cadaveric education was incomplete in completing the perception of reality in surgical lessons, almost all students agreed that anatomy education with only models and digital software will be insufficient in medical education. Those who disagree with the opinion in this question and undecided are very few. The conclusion to be drawn here is that touching, perceiving and manipulating the human body requires an enormous training. For the three-dimensional structure and mystery of the human body, the cadaver is a very important and precious lesson tool that is hard to find, even it is insufficient to meet the real tissue perception of reality.

The indispensable part of anatomy education for the sense of perception and reality is cadavers. The anatomy lesson, on the other hand, must renew itself in three-dimensional perception apart from the traditional systematic anatomy and be supported by technological innovations (Zumwalt et al., 2010). Because the basis of clinical anatomy such as ultrasonographic anatomy, radiological anatomy, laparoscopic anatomy and cross-sectional anatomy, which should be mastered in the surgical and clinical classes of medical education, is also very necessary for students (Sure et al., 2005; Orsbon et al., 2014). Students' opinions on this subject support this situation. In order for anatomy to develop itself and keep up with technology, clinical branches and anatomy branches should be integrated with each other (Morgan et al., 2017).

\section{Conclusion}

This study was conducted for the importance and awareness of the integration of clinical and anatomy branches with each other. Student opinions were taken to emphasize the importance of the study. As a result of these views, it was tried to be revealed with quantitative data both how anatomy education should be given and the importance of anatomy education in its interaction with surgical branches.

Ethics Committee Approval: The study was approved by the ethics committee of Faculty of Health Sciences Kars University (Approval number: 2020/6/decision 01). The study was performed following the aid of the ethical standards down in the 1964 Declaration of Helsinki and its later amendments.

Peer-review: Externally peer-reviewed.

Author Contributions: Concept- E.B, T.D.A.; Design- E.B, T.D.A.; Materials- E.B.; Data Collection and Processing- E.B.; Literature ReviewE.B, T.D.A.; Writing- E.B, T.D.A.; Critical ReviewE.B, T.D.A.

Conflict of Interest: No conflict of interest was declared by the author.

Financial Disclosure: The author declared that this study hasn't received no financial support.

\section{References}

Are C, Stoddard HA, Northam LC, Thompson JS, Todd GL. An experience in surgical anatomy to provide first-year medical students with an early exposure to general surgery: a pilot study. Journal of surgical education 2009; 66(4): 186-189.

Bahsi I, Topal Z, Cetkin M, Orhan M, Kervancioglu $\mathrm{P}$, Odabasioglu ME, Cihan OF. Evaluation of attitudes and opinions of medical faculty students against the use of cadaver in anatomy education and investigation of the factors affecting their emotional responses related thereto. Surgical and Radiologic Anatomy 2020: 1-7.

Bahsi I, Cetkin, M, Orhan M, Kervancioglu P, Sayin $\mathrm{S}$, Ayan H. Evaluation of attention-motivation level, studying environment and methods of medical faculty students. European Journal of Therapeutics 2017; 23(1): 1-7.

Biasutto, SN, Caussa LI, Río LEC. Teaching anatomy: cadavers vs. computers? Annals of Anatomy-Anatomischer Anzeiger 2006; 188(2): 187-190.

Cetkin M, Turhan B, Bahsi I, Kervancioglu P. The opinions of medicine faculty students about anatomy education. European Journal of Therapeutics 2016; 22: 82-88.

Estai M, Bunt S. Best teaching practices in anatomy education: A critical review. Annals of AnatomyAnatomischer Anzeiger 2016; 208: 151-157. 
Fitzpatrick CM, Kolesari GL, Brasel KJ. Teaching anatomy with surgeons' tools: Use of the laparoscope in clinical anatomy. Clinical Anatomy: The Official Journal of the American Association of Clinical Anatomists and the British Association of Clinical Anatomists 2001; 14(5): 349-353.

Heisler CA. Importance of adequate gross anatomy education: the impact of a structured pelvic anatomy course during gynecology fellowship. Anatomical sciences education 2011; 4(5): 302304.

Hoyek N, Collet C, Di Rienzo F, De Almeida M, Guillot A. Effectiveness of three-dimensional digital animation in teaching human anatomy in an authentic classroom context. Anatomical sciences education 2014;7(6):430-437.

Gozil R, Ozkan S, Bahcelioglu M, Kadioglu D, Calguner E, Öktem H, Babus T. Gazi Universitesi Tıp Fakultesi 2. Sınıf Ögrencilerinin Anatomi Egitimini Degerlendirmeleri. Tip Egitimi Dunyası 2006; 23(23): 27-32.

Gunderman RB, Wilson PK. Exploring the human interior: The roles of cadaver dissection and radiologic imaging in teaching anatomy. Academic Medicine 2005;80(8):745-749.

Kagan I I. Traditions and peculiarities of clinical anatomy education in Russia. Clinical Anatomy: The Official Journal of the American Association of Clinical Anatomists and the British Association of Clinical Anatomists 2002; 15(2): 152-156.

Lewis TL, Burnett B, Tunstall RG, Abrahams PH. Complementing anatomy education using threedimensional anatomy mobile software applications on tablet computers. Clinical Anatomy 2014; 27(3):313-320.

McLachlan JC, Bligh, J, Bradley P, Searle J. Teaching anatomy without cadavers. Medical education 2004; 38(4): 418-424.

Morgan H, Zeller J, Hughes DT, Dooley-Hash S, Klein K, Caty R, Santen S. Applied clinical anatomy: the successful integration of anatomy into specialty-specific senior electives. Surgical and Radiologic Anatomy 2017;39(1): 95-101.

Murgitroyd E, Madurska M, Gonzalez J,Watson A. $3 \mathrm{D}$ digital anatomy modelling-Practical or pretty? The Surgeon 2015; 13(3):177-180.

Orsbon CP, Kaiser RS, Ross CF. Physician opinions about an anatomy core curriculum: A case for medical imaging and vertical integration. Anatomical sciences education 2014;7(4): 251261.

Older J. Anatomy: a must for teaching the next generation. The Surgeon 2004; 2(2): 79-90.
Ozcan S, Huri E, Tatar I, Sargon M, Karakan T, Yagli OF, Larre S. Impact of cadaveric surgical anatomy training on urology resident's knowledge: a preliminary study. Turkish journal of urology 2015; 41(2):83.

Rizzolo LJ, Stewart WB. Should we continue teaching anatomy by dissection when? The Anatomical Record Part B: The New Anatomist: An Official Publication of the American Association of Anatomists 2006; 289(6): 215-218. Singh R, Tubbs RS, Gupta K, Singh M, Jones DG, Kumar R. Is the decline of human anatomy hazardous to medical education/profession?-A review. Surgical and Radiologic Anatomy 2015; 37(10): 1257-1265.

Sugand K, Abrahams P, Khurana A. The anatomy of anatomy: a review for its modernization. Anatomical sciences education 2010; 3(2): 83-93.

Sure U, Benes L, Bozinov O, Woydt M, Tirakotai W, Bertalanffy $H$. Intraoperative landmarking of vascular anatomy by integration of duplex and Doppler ultrasonography in image-guided surgery. Technical note. Surgical neurology 2005;63(2): 133-142.

Zumwalt AC, Lufler RS, Monteiro J, Shaffer K. Building the body: Active learning laboratories that emphasize practical aspects of anatomy and integration with radiology. Anatomical sciences education 2010;3(3): 134-140. 